\title{
Nonimmunoglobulin E-Mediated Immune Reactions to Foods
}

\author{
Jonathan M. Spergel, MD, PhD
}

\begin{abstract}
Adverse food reactions are abnormal responses to ingested foods. Reactions vary from immunologic to nonimmunologic immune reactions and can be either immunoglobulin $\mathrm{E}(\mathrm{IgE})$ mediated or non-lgE mediated. Food-induced IgE-mediated reactions range from localized urticaria to anaphylaxis and have been well studied. However, in comparison, there has been significantly less research into non-IgEmediated food reactions. Non-IgE-mediated reactions can cause respiratory, gastrointestinal, and cutaneous symptoms. The most recent evidence suggests that these reactions are probably T-cell mediated as evidenced in lymphocyte proliferation assays. This review will explore the symptoms and testing methods of the most common non-IgE-mediated reactions.
\end{abstract}

An adverse food reaction is any abnormal response to an ingested food, regardless of the pathophysiology. One classification scheme separates immunologic from nonimmunologic entities. Nonimmune reactions include jitteriness from caffeine and metabolic disorders such as lactase deficiency. Immune reactions are divided into those that are immunoglobulin E (IgE)-mediated and those that are not IgE mediated. IgE-mediated reactions are the classic presentations of food allergy, such as hives or anaphylaxis after ingestion of the offending food antigen. Non-IgE-mediated food reactions have been described in the

J.M. Spergel-Assistant Professor of Pediatrics, Division of Allergy and Immunology, Department of Pediatrics, The Children's Hospital of Philadelphia, University of Pennsylvania School of Medicine, Philadelphia, Pennsylvania

Correspondence to: Dr. Jonathan M. Spergel, e-mail: spergel@email.chop.edu

DOI 10.2310/7480.2006.00009 last several years and include food protein-induced enterocolitis syndrome and allergic eosinophilic esophagitis. Non-IgE-mediated food reactions are classified as negative skin test results or specific IgE to foods, with positive challenge to the offending food. The reactions can vary by system, from gastrointestinal (GI) to cutaneous to respiratory; gastrointestinal reactions are the most common reactions (Table 1).

In regard to biology and documentation, foodspecific non-IgE-mediated reactions are currently not as well understood as IgE-mediated reactions are. The greatest insight into their pathophysiology comes from the identification of food-specific $\mathrm{T}$ cells in atopic dermatitis (AD). Food-specific skin-homing cutaneous lymphocyte antigen $\left(\mathrm{CLA}^{+}\right) \mathrm{T}$ cells have been identified in the lesions of milk-allergic patients who have AD. ${ }^{1}$ These patients have a flare of their AD when challenged by milk. Milk-sensitive patients with GI symptoms on challenge or the control group (nonmilk-allergic) patients did not have milkspecific CLA ${ }^{+} \mathrm{T}$ cells.

Additional evidence of the role of $\mathrm{T}$ cells in non-IgE-mediated food allergy is found in atopy food patch testing of persons with AD. Atopy 
Table 1

\begin{tabular}{|c|c|c|c|}
\hline Disorder & Symptoms & Diagnostic Testing & Food Involved \\
\hline \multicolumn{4}{|l|}{ Cutaneous } \\
\hline Atopic dermatitis & Chronic relapsing pruritic rash & $\begin{array}{l}\text { Skin testing and atopy } \\
\text { patch testing }\end{array}$ & $\begin{array}{l}\text { Milk, eggs, soy, } \\
\text { peanuts, wheat }\end{array}$ \\
\hline $\begin{array}{l}\text { Dermatitis } \\
\text { herpetiformis }\end{array}$ & $\begin{array}{l}\text { Marked pruritus; } \\
\text { papulovesicular rash over } \\
\text { extensor surfaces and } \\
\text { buttocks }\end{array}$ & $\begin{array}{l}\text { Skin biopsy (IgA } \\
\text { deposition), IgA antigliadin } \\
\text { and antitransglutaminase } \\
\text { antibodies; } \pm \text { endoscopy }\end{array}$ & Gluten \\
\hline \multicolumn{4}{|l|}{ Gastrointestinal } \\
\hline FPIES & $\begin{array}{l}\text { Vomiting, diarrhea, progressing } \\
\text { to shocklike state }\end{array}$ & Elimination diet, patch testing & Milk, soy, others \\
\hline $\begin{array}{r}\text { Eosinophilic } \\
\text { esophagitis }\end{array}$ & $\begin{array}{l}\text { Gastroesophageal reflux } \\
\text { symptoms, dysphagia, failure } \\
\text { to thrive }\end{array}$ & $\begin{array}{l}\text { Elimination diet, skin testing } \\
\text { and patch testing }\end{array}$ & Multiple foods \\
\hline Celiac disease & $\begin{array}{l}\text { Weight loss, chronic diarrhea, } \\
\text { steatorrhea, abdominal } \\
\text { distention }\end{array}$ & $\begin{array}{l}\text { IgA antigliadin and } \\
\text { antitransglutaminase } \\
\text { antibodies, endoscopy }\end{array}$ & Gluten \\
\hline \multicolumn{4}{|l|}{ Respiratory } \\
\hline $\begin{array}{l}\text { Pulmonary } \\
\text { hemosiderosis }\end{array}$ & $\begin{array}{l}\text { Recurrent pneumonia, } \\
\text { pulmonary infiltrates, iron } \\
\text { deficiency anemia, failure } \\
\text { to thrive }\end{array}$ & $\begin{array}{l}\text { Clinical history, peripheral } \\
\text { eosinophilia, milk precipitins } \\
\text { (if caused by milk), } \pm \text { lung } \\
\text { biopsy, elimination diet }\end{array}$ & Milk, eggs \\
\hline
\end{tabular}

FPIES $=$ food protein-induced enterocolitis syndrome; IgA = immunoglobulin A.

patch tests have a high specificity, and double-blind food challenges indicate their reliability. ${ }^{2,3}$ These patients often have IgE-negative disease as determined by skin testing or in vitro assay. Patch testing is generally believed to reflect $\mathrm{T}$ cell-mediated reactions because allergen-specific $\mathrm{T}$ cells can be isolated from biopsy sites of patch-test reactions to inhalant allergens. ${ }^{4,5}$ The isolated $\mathrm{T}$ cells are skewed toward the Thelper 2 (Th2) phenotype in food-sensitive AD patients. In addition, most isolated $\mathrm{CLA}^{+} \mathrm{T}$ cells have a Th2 phenotype.

Bellanti and colleagues examined T-cell phenotypes in a group of patients with GI food allergies. ${ }^{6}$ The symptoms were confirmed by double-blind placebo-controlled food challenges. These patients had non-IgE-mediated disease as all 12 patients had negative results on immediate-type skin testing and negative results on IgE radioallergosorbent tests (RASTs). These patients were compared with four patients with celiac disease. Investigators found normal peripheralblood CD4 and CD8 lymphocyte distributions in the food-allergic patients, as compared to abnormal CD4/CD8 ratios in the celiac disease group. As compared with the celiac disease patients, there was a predominance of $\mathrm{CD} 4^{+}$cells with a decreased intracellular Th1 cytokine pattern and a normal Th2 intracellular cytokine pattern, indicating a role of Th1 cells as a key mechanism in non-IgE-mediated reactions. A similar abnormal pattern of CD4/CD8 ratio was observed in intestinal biopsy specimens from the 12 patients. ${ }^{6}$ Thus, both populations of $\mathrm{CD}^{+}$cells may be involved in non-IgE-mediated reactions (Th1 cells in GI reactions and the $\mathrm{CLA}^{+}$cells in $\mathrm{AD}$ reactions).

\section{Non-IgE-Mediated Skin Reactions: Dermatitis Herpetiformis}

Dermatitis herpetiformis presents as a chronic blistering pruritic papulovesicular rash symmetrically distributed over extensor surfaces and over 
the buttocks. It can be associated with celiac disease with sensitivity to gluten. Dermatopathologic examination of the skin reveals immunoglobulin A ( $\operatorname{Ig} \mathrm{A})$ deposits in the dermo-epidermal junctions whereas GI lesions resemble celiac disease. ${ }^{7}$ Analysis of sera shows positive IgA antigliadin and antitransglutaminase antibodies consistent with celiac disease. ${ }^{8}$

\section{Mixed IgE-Mediated and Non-IgE-Mediated Skin Reactions: Atopic Dermatitis}

$\mathrm{AD}$ is a chronic inflammatory skin disorder and the most common childhood disease, having a prevalence of 10 to $15 \%$ in the United States. Unlike many other diseases, however, AD has no single diagnostic feature or pathognomonic test. The major features include pruritus, typical morphology, and distribution of the lesions. In infancy, the face and the extensor surfaces of the arms and legs are most commonly affected. In older children and adults, a scaly and lichenified dermatitis on the flexor surfaces of the extremities, neck, and upper trunk is observed..$^{9} 10$ The role of food allergy in $\mathrm{AD}$ has been reviewed extensively, and food allergy has been shown clearly to play a role in pathogenesis in 10 to $30 \%$ of patients with moderate to severe atopic dermatitis. ${ }^{11}$ Of interest, foods can trigger AD by both IgE-mediated and non-IgE-mediated mechanisms. Clinical studies have shown that skin test (sera-specific IgE or atopy patch test) results correlate with flaring of AD during double-blind food challenge. ${ }^{12,13}$

Additional evidence for a mixed mechanism has developed from clinical observation. Ninety percent of patients with AD have markedly elevated total IgE levels and high levels of specific IgE. The clinical removal of the allergens that react with the specific $\mathrm{IgE}$ of the patient can decrease AD symptoms in the affected patient. ${ }^{14}$

The role of T cells is confirmed by skin biopsy specimens showing $\mathrm{T}$ cell-infiltrated lesions and expression of CLA, a homing receptor for T lymphocytes to the skin. CLA interacts with E-selectin expressed on activated vascular endothelium in affected areas. Th 2 cells predominate in the acute lesions whereas Th1 and Th2 cells are found in the chronic eczematous lesions. ${ }^{15}$ Several studies have elucidated the role of food allergen-specific $\mathrm{T}$ cells in the inflammatory process underlying AD. The best evidence is that food allergen-specific $\mathrm{T}$ cells have been cloned from active skin lesions and healthy skin of patients with AD. ${ }^{16,17}$ Reekers and colleagues found that $\mathrm{T}$ cells isolated from the skin biopsy sites and peripheral blood react to foods related to birch pollen, and clinical reactivity was confirmed by double-blind placebo-controlled food challenges. ${ }^{17}$ In addition, patients with milkinduced AD were studied and compared with control subjects who had milk-induced GI reactions without $\mathrm{AD}$ and with nonatopic control subjects. Casein-reactive $\mathrm{T}$ cells from the children with milk-induced AD had a significantly higher expression of CLA than did other antigen-specific $\mathrm{T}$ cells from the same patients or from the control groups. ${ }^{1}$ Taken together, these studies examining the role of allergic responses to food in the pathogenesis of AD indicate a mixed inflammatory response involving $\mathrm{T}$ cells and IgE-mediated reactions.

\section{Non-IgE-Mediated Gastrointestinal Disorders}

\section{Food Protein-Induced Enterocolitis Syndrome}

Food protein-induced enterocolitis syndrome (FPIES), whose symptoms include vomiting, diarrhea, lethargy, and dehydration, can progress to a severe shocklike state. ${ }^{18,19}$ Most patients with FPIES present in the first months of life, and the disorder typically resolves by 2 years of age but can persist (in rare cases) into later childhood. Most patients with FPIES have negative reactions to the offending food on skin and/or nonreactive food-specific IgE tests. As opposed to the immediateness of IgE-mediated reactions, the onset of the symptoms of FPIES is delayed from 1 to 10 hours, with a median of 2 hours after the ingestion of food. Symptoms typically start with emesis that often is followed by diarrhea. ${ }^{19}$ As with IgEmediated reactions, cow's milk and soy proteins are the antigens most commonly responsible for 
FPIES in infants. ${ }^{20}$ Recently, FPIES has been reported from grains (rice, oats, and barley), vegetables (sweet potatoes, squash, string beans, and peas), and poultry (chicken and turkey). ${ }^{21}$

The only reported laboratory findings in FPIES are an increase in peripheral-blood neutrophil counts during a positive challenge, an alteration in levels of tumor necrosis factor- $\alpha$ in the feces, and the secretion of peripheral-blood mononuclear cells. ${ }^{18,22}$ The pathophysiology of FPIES is incompletely understood. ${ }^{20}$ FPIES is thought to be a $\mathrm{T}$ cell-mediated disease because most of these patients have negative skin test reactions to the offending antigen. Evaluation for T-cell function has shown that antigen-specific $\mathrm{T}$ cells proliferate to milk and soy in patients with FPIES induced by milk and soy, ${ }^{23}$ but this response can also be seen in healthy individuals. In a case report of FPIES from rice, Gray and colleagues found that the results of in vitro lymphoproliferative assays for rice were positive. ${ }^{24}$ In addition, there was increased cytokine synthesis of interferon- $\gamma$, interleukin (IL)-10, tumor necrosis factor- $\alpha$, and IL-5 in the patient with rice FPIES. Finally, the authors isolated and expanded duodenal explant $\mathrm{T}$ cells with rice and IL-2 stimulation for 2 days. After a 2-day rest, the lymphocytes were re-stimulated with rice for 7 days; increased interferon- $\gamma$ and IL5 synthesis were revealed, indicating a Th1- and Th2-cell response to rice. This study provides evidence for a T-cell mechanism in FPIES.

We have found that atopy patch tests provided a highly specific way to identify children with FPIES. In our preliminary studies of 15 children, all children with negative atopy patch-test results had negative results on food challenge whereas $90 \%$ of the positive patch-test results correlated with positive results on challenge (data in press). The exact mechanism of FPIES is unknown; it is clearly not IgE. Most evidence suggests a $\mathrm{T}$ cell-driven process.

\section{Celiac Disease}

Celiac disease is a specific food protein-induced autoimmune enteropathy in which the body reacts to gliadin, the alcohol-soluble portion of gluten found in wheat, oats, rye, and barley. ${ }^{9}$ It is the most common intestinal disorder of Western populations and occurs in genetically susceptible individuals carrying the human leukocyte antigen (HLA)DQ2 or HLA-DQ8 haplotype. Typical symptoms include weight loss, chronic diarrhea, steatorrhea, and associated abdominal distention and oral ulcers. Diagnosis is made by documentation of typical abnormalities (villous atrophy and cellular infiltrate) that are reversed by the elimination of gliadin from the diet. Most patients produce IgA antigliadin and antiendomysial antibodies. ${ }^{7}$ Of interest, the early introduction of wheat into the diet (before the age of 3 months, compared to 6 months) was associated with fivefold higher risk of celiac disease as based on HLA phenotype in a prospective study of 1,560 high-risk infants in Denver, Colorado. This finding indicates that the early introduction of offending foods in high-risk populations can increase disease prevalence. ${ }^{25}$

In terms of pathogenesis, celiac disease represents a unique model because both an external trigger (the gluten peptides) and the autoantigen (the ubiquitous enzyme tissue transglutaminase) have been identified. Furthermore, the gluten peptides behave with two different mechanisms in the disease process, some fragments being "toxic" and others being "immunogenic."26 The "toxic" peptides are able to induce mucosal damage while the "immunogenic" peptides are able to specifically stimulate HLA-DQ2-restricted or HLADQ8-restricted T-cell clones. These peptides trigger two immunologic pathways: (1) a rapid effect on the epithelium, involving the innate immune response, and (2) an adaptive immune response involving $\mathrm{CD}^{+} \mathrm{T}$ cells in the lamina propria that recognize gluten epitopes processed and presented by antigen-presenting cells.

\section{Combined IgE-Mediated and T Cell-Mediated Gastrointestinal Disorders: Eosinophilic Esophagitis}

Eosinophilic esophagitis (EE), primary or idiopathic, occurs in both adults and children. ${ }^{27}$ Patients with EE present with symptoms similar to those of gastroesophageal reflux disease (GERD) but are unresponsive to anti-reflux medication and have normal hydrogen ion concentration $(\mathrm{pH})$ probe 
study results. Vomiting and abdominal pain are the most common symptoms ${ }^{28}$; other common symptoms include anemia (occult blood loss), weight loss, ${ }^{29}$ achalasia, ${ }^{30}$ and failure to thrive.

Published case series that examined EE in children have indicated that food allergy can play a causative role. Kelly and colleagues examined 23 children with classic symptoms of GERD whose symptoms did not improve with standard treatment for 6 to 78 months. ${ }^{31}$ Eosinophil counts in esophageal biopsy specimens were elevated at 15 to 100 eosinophils per high-power field (HPF), compared with standard GERD eosinophil levels of $<5$ eosinophils per HPF. Seventeen patients were offered an elemental diet with an enteral nutritional supplement (Neocate or EleCare); 12 patients completed dietary treatment, and all 12 patients reported symptom improvement. Repeat esophageal biopsies in 10 patients revealed decreased eosinophil counts (5-30 eosinophils per HPF). Eight patients had normal biopsy specimens ( $<5$ eosinophils per HPF). The remaining two patients had improvement but not a complete resolution (repeat eosinophil counts of 10 and 30 eosinophils, respectively, and improvement from 20 and 90 eosinophils per HPF, respectively). Foods were introduced into their diets at home. Milk was identified as causing symptoms in 7 patients; soy, in 4 patients; wheat, in 2 patients; peanuts, in 2 patients; and eggs, in 1 patient. Interestingly, 3 of the 10 patients had negative skin-prick test results for foods. In addition, 7 of the 10 patients denied experiencing any IgE-mediated symptoms or immediate reactions to foods, which suggests a role for non-IgE-mediated food reactions.

Orenstein and colleagues ${ }^{27}$ tried to link food allergies to EE more definitively. They studied 30 patients with EE retrospectively on the basis of elevated eosinophils in biopsy specimens. The patients were subsequently divided into two groups: 9 patients with 5 to 20 eosinophils per HPF and 21 patients with $>20$ eosinophils per HPF. The 21 patients with $>20$ eosinophils per HPF had symptoms that were similar to those of patients in other studies, including recurrent esophageal food impactions, vomiting, pain, and dysphagia. This select population had a strong atopic background; $62 \%$ of the patients had a history of allergy. Food allergy testing was done in 19 children by skin test- ing, by RAST, or by both methods. Six children had negative results with both methods. Twelve of 13 patients with documented food allergies were given an elimination diet; 2 patients were noncompliant, but 10 patients showed symptom improvement, and 7 of the 10 patients received other treatments. ${ }^{27}$ This study highly suggests that food allergies can play a significant role in EE in this group. The nine children with 5 to 20 eosinophils per HPF had similar results: 3 of 5 tested patients had positive results on food testing. One of the three children had a good response to diet, one was noncompliant, and the final child had a poor response. In both Kelly and colleagues' and Orenstein and colleagues' studies, about $30 \%$ of the patients had negative responses to food testing for IgE-mediated reactions but complete responses to diet elimination, suggesting a non-IgE-mediated mechanism. The concept of foods as causative agents was confirmed in the work by Markowitz and colleagues, who found that all of their study's 51 patients with EE improved on an elemental diet. ${ }^{32}$

The concept of a mixed IgE and non-IgE mechanism was confirmed in our work. We performed skin testing as well as atopy patch testing with 26 patients in our first published series ${ }^{33}$ and with 154 patients in our most recent series. ${ }^{34}$ Ninety-six percent (135 of 140) of the patients who completed the diet regimen improved on a restriction diet, clearly indicating that foods cause EE. About one-third of the patients had negative skin test results for all foods, and $18 \%$ had negative patch-test results for all foods; there was little overlap in the groups as less than $4 \%$ of patients had negative results on both skin tests and atopy patch tests. In $90 \%$ of the cases, foods identified by skin testing (IgE mediated) were different from foods identified by atopy patch testing (non-IgE mediated). These results indicate a mixed mechanism for food-induced reactions in EE.

\section{Non-IgE-Mediated Respiratory Reactions: Food-Induced Pulmonary Hemosiderosis}

Food-induced pulmonary hemosiderosis (Heiner's syndrome) is a rare disorder, typically associated with milk or egg. It is characterized by pulmonary 
infiltrates associated with hemosiderosis, GI blood loss, anemia, and failure to thrive. ${ }^{35}$ The immune mechanisms underlying food-induced pulmonary hemosiderosis are unknown. What suggests a non-IgE-mediated process is that patients have negative results on skin tests and in vitro $\mathrm{IgE}$ analysis, but in an isolated report of pulmonary hemosiderosis from buckwheat, the patients had positive patch-test results. ${ }^{36,37}$ These patients had T-cell proliferation from the offending antigens (including milk, eggs, and other foods), ${ }^{36}$ suggesting a T-cell pathophysiology similar to that of other non-IgE-mediated reactions.

\section{Clinical Tests for Non-IgE-Mediated Reactions}

The general history and examination will lead to a list of suspected foods (if any) and determine the likelihood for non-IgE-mediated or T cell-mediated processes. Obtaining an accurate clinical history is more difficult in the case of non-IgE-mediated reactions as compared to IgE-mediated reactions because of the delay in the onset of symptoms after ingestion of the food. IgE-mediated reactions typically occur seconds to 2 hours after ingestion of the food and have a clear clinical pattern. In the case of non-IgE-mediated reactions, the onset of symptoms after ingestion of food can be delayed, from hours to a day after ingestion. Also, symptoms can vary, from severe symptoms in FPIES patients to subtle reactions in EE patients, with gradual worsening of dysphagia over weeks.

In addition, fewer laboratory diagnostic tools exist for non-IgE-mediated disorders than for IgE-mediated reactions. Food patch testing has been studied for AD, EE, Heiner's syndrome, and (recently) FPIES, with some encouraging results. Although the atopy patch test shows promise for identifying foods that might elicit non-IgEmediated reactions, there are no standardized reagents at this time, making results difficult to interpret. Nonspecific irritation is a common finding in standard patch testing and therefore requires skill in interpretation. ${ }^{38}$ However, progress in standardization is occurring; the typical application is for 48 hours, and results are read 24 hours later.
The European Task Force on Atopic Dermatitis has developed standard reading methods with good reproducibility. ${ }^{4}$ As additional work is being done in standardizing the reagents, atopy patch tests may be a useful tool for identifying food-induced non-IgE-mediated reactions.

Some preliminary studies measuring T-cell proliferation from food antigens have shown encouraging results in selected patients. ${ }^{17,24,39,40}$ One of the major drawbacks is that lymphocyte proliferation can occur in normal controls under certain conditions. Measurement of immunoglobulin $\mathrm{G}$ has not been helpful in most non-IgEmediated food reactions.

In celiac disease and dermatitis herpetiformis, antibodies to TTG and IgA antigliadin and antiendomysial antibodies correlate with expression of the disease. However, diagnosis is often confirmed by biopsy while the patient is on and off a glutenfree diet; typical changes of villous atopy will be noted in biopsy specimens obtained during the gluten phase of the diet.

\section{Oral Food Challenges}

Since there is no predictive or diagnostic test, oral food challenge remains the "gold standard." The most rigorous method is double blind and placebo controlled, but single-blind (ie, the patient) and open-label challenges can be performed. Doubleblind placebo-controlled challenges are indicated when the endpoints are subjective complaints (ie, bias is possible) or when there are specific research objectives. The challenge procedure involves giving increasing doses at intervals during constant observation. The starting dose is sufficiently low to avoid triggering a severe reaction $(\mathrm{eg}, \approx 100$ $500 \mathrm{mg})$. Intervals are shorter $(\approx 20$ minutes $)$ when testing for IgE-mediated processes rather than for T cell-mediated processes (hours, for example, for FPIES). Once the top dose is reached, the observation period varies: 2.5 hours for IgEmediated reactions and 4 hours for T cell-mediated processes (eg, FPIES). Longer periods and multiple doses may be required to elicit a reaction in patients with some disorders (eg, EE). For EE cases, biopsies are needed to confirm the results making food challenges. Therefore, definitive 
diagnostic procedures are more time consuming in cases of non-IgE-mediated reactions than in cases of IgE-mediated reactions. When a food challenge is unsuccessful, repeat challenge is recommended every 6 months to 2 years, depending on the clinical severity of the reaction.

\section{Conclusion}

Non-IgE-mediated food reactions are being reported with increasing frequency. Reactions can vary from flaring of atopic dermatitis (AD) to food-induced protein enterocolitis syndrome (FPIES). The exact mechanism is unknown, but most studies suggest a $\mathrm{T}$ cell-mediated pathophysiology, as food-specific $\mathrm{T}$ cells can be identified in FPIES and AD patients. One of the most difficult problems in identifying and treating non-IgE-mediated reactions is the lack of standardized testing protocols and the difficulty of obtaining an accurate clinical history. Atopy patch testing may be a promising method for identifying causative foods and has shown progress in $\mathrm{EE}$ and AD cases. Additional clinical and translational research is needed in this field to further our knowledge of non-IgE-mediated food reactions.

\section{References}

1. Abernathy-Carver KJ, Sampson HA, Picker LJ, Leung DY. Milk-induced eczema is associated with the expansion of $\mathrm{T}$ cells expressing cutaneous lymphocyte antigen. J Clin Inves 1995;95:913-8.

2. Majamaa H, Moisio P, Holm K, et al. Cow's milk allergy: diagnostic accuracy of skin prick and patch tests and specific IgE. Allergy 1999;54:346-51.

3. Majamaa H, Moisio P, Holm K, Turjanmaa K. Wheat allergy: diagnostic accuracy of skin prick and patch tests and specific IgE. Allergy 1999;54:851-6.

4. Darsow U, Laifaoui J, Kerschenlohr K, et al. The prevalence of positive reactions in the atopy patch test with aeroallergens and food allergens in subjects with atopic eczema: a European multicenter study. Allergy 2004;59:1318-25.
5. Wittmann M, Alter M, Stunkel T, et al. Cell-tocell contact between activated $\mathrm{CD} 4+\mathrm{T}$ lymphocytes and unprimed monocytes interferes with a TH1 response. J Allergy Clin Immunol 2004;114:965-73.

6. Bellanti JA, Zeligs BJ, Malka-Rais J, Sabra A. Abnormalities of Th1 function in non-IgE food allergy, celiac disease, and ileal lymphonodular hyperplasia: a new relationship? Ann Allergy Asthma Immunol 2003;90(6 Suppl 3):84-9.

7. Poon E, Nixon R. Cutaneous spectrum of coeliac disease. Australas J Dermatol 2001;42:136-8.

8. Zone JJ. Skin manifestations of celiac disease. Gastroenterology 2005;128(4 Suppl 1):S87-91.

9. Spergel J, Schneider L. Atopic dermatitis. Internet J Asthma Allergy Immunol 1997;1.

10. Spergel JM, Paller AS. Atopic dermatitis and the atopic march. J Allergy Clin Immunol 2003;112(6 Suppl):S118-27.

11. Sicherer SH, Sampson HA. Food hypersensitivity and atopic dermatitis: pathophysiology, epidemiology, diagnosis, and management. J Allergy Clin Immunol 1999;104(3 Pt 2):S114-22.

12. Niggemann B, Reibel S, Wahn U. The atopy patch test (APT) - a useful tool for the diagnosis of food allergy in children with atopic dermatitis. Allergy 2000;55:281-5.

13. Sampson HA, Ho DG. Relationship between food-specific IgE concentrations and the risk of positive food challenges in children and adolescents. J Allergy Clin Immunol 1997;100:444-51.

14. Leung DY, Bieber T. Atopic dermatitis. Lancet 2003;361:151-60.

15. Grewe M, Walther S, Gyufko K, et al. Analysis of the cytokine pattern expressed in situ in inhalant allergen patch test reactions of atopic dermatitis patients. J Invest Dermatol 1995;105:407-10.

16. Beyer K, Castro R, Feidel C, Sampson HA. Milkinduced urticaria is associated with the expansion of T cells expressing cutaneous lymphocyte antigen. J Allergy Clin Immunol 2002;109:688-93.

17. Reekers R, Busche M, Wittmann M, et al. Birch pollen-related foods trigger atopic dermatitis in patients with specific cutaneous T-cell responses to birch pollen antigens. J Allergy Clin Immunol 1999;104(2 Pt 1):466-72.

18. Dupont C, Heyman M. Food protein-induced enterocolitis syndrome: laboratory perspectives. 
J Pediatr Gastroenterol Nutr 2000;30 Suppl:S50-7.

19. Sicherer SH. Food protein-induced enterocolitis syndrome: clinical perspectives. J Pediatr Gastroenterol Nutr 2000;30 Suppl:S45-9.

20. Sicherer S, Eigenmann P, Sampson H. Clinical features of food protein-induced enterocolitis syndrome. J Pediatr 1998;133:214-9.

21. Nowak-Wegrzyn A, Sampson HA, Wood RA, Sicherer SH. Food protein-induced enterocolitis syndrome caused by solid food proteins. Pediatrics 2003;111(4 Pt 1):829-35.

22. Benlounes N, Dupont C, Candalh C, et al. The threshold for immune cell reactivity to milk antigens decreases in cow's milk allergy with intestinal symptoms. J Allergy Clin Immunol 1996;98:781-9.

23. Van Sickle GJ, Powell GK, McDonald PJ, Goldblum RM. Milk- and soy protein-induced enterocolitis: evidence for lymphocyte sensitization to specific food proteins. Gastroenterology 1985;88:1915-21.

24. Gray HC, Foy TM, Becker BA, Knutsen AP. Rice-induced enterocolitis in an infant: TH1/TH2 cellular hypersensitivity and absent IgE reactivity. Ann Allergy Asthma Immunol 2004;93:601-5.

25. Norris JM, Barriga K, Hoffenberg EJ, et al. Risk of celiac disease autoimmunity and timing of gluten introduction in the diet of infants at increased risk of disease. JAMA 2005;293:2343-51.

26. Ciccocioppo R, Di Sabatino A, Corazza GR. The immune recognition of gluten in coeliac disease. Clin Exp Immunol 2005;140:408-16.

27. Orenstein SR, Shalaby TM, Di Lorenzo C, et al. The spectrum of pediatric eosinophilic esophagitis beyond infancy: a clinical series of 30 children. Am J Gastroenterol 2000;95:1422-30.

28. Brown K. Eosinophilic enteritis. In: Altschuler S, Liacouras C, editors. Clinical pediatric gastroenterology. Philadelphia: Churchill Livingstone; 1998.

29. Katz A, Twarog F, Zeiger R, Falchuk Z. Milksensitive and eosinophilic gastroenteropathy: similar clinical features with contrasting mech- anisms and clinical course. J Allergy Clin Immunol 1984;74:72-8.

30. Landres RT, Kuster GG, Strum WB. Eosinophilic esophagitis in a patient with vigorous achalasia. Gastroenterology 1978;74:1298-301.

31. Kelly KJ, Lazenby AJ, Rowe PC, et al. Eosinophilic esophagitis attributed to gastroesophageal reflux: improvement with an amino acid-based formula. Gastroenterology 1995;109:1503-12.

32. Markowitz JE, Spergel JM, Ruchelli E, Liacouras CA. Elemental diet is an effective treatment for eosinophilic esophagitis in children and adolescents. Am J Gastroenterol 2003;98:777-82.

33. Spergel JM, Beausoleil JL, Mascarenhas M, Liacouras CA. The use of skin prick tests and patch tests to identify causative foods in eosinophilic esophagitis. J Allergy Clin Immunol 2002;109:363-8.

34. Spergel J, Andrews T, Brown-Whitehorn T, et al. Treatment of eosinophilic esophagitis with specific food elimination diet directed by a combination of prick skin test and patch tests. Ann Allergy Asthma Immunol 2005. [DOI ]

35. Lee SK, Kniker WT, Cook CD, Heiner DC. Cow's milk-induced pulmonary disease in children. Adv Pediatr 1978;25:39-57.

36. Kondo N, Fukutomi O, Agata H, Yokoyama Y. Proliferative responses of lymphocytes to food antigens are useful for detection of allergens in nonimmediate types of food allergy. J Investig Allergol Clin Immunol 1997;7:122-6.

37. Agata H, Kondo N, Fukutomi O, et al. Pulmonary hemosiderosis with hypersensitivity to buckwheat. Ann Allergy Asthma Immunol 1997;78:233-7.

38. Spergel JM, Brown-Whitehorn T. The use of patch testing in the diagnosis of food allergy. Curr Allergy Asthma Rep 2005;5:86-90.

39. Dorion BJ, Leung DY. Selective expansion of $T$ cells expressing $\mathrm{V}$ beta 2 in peanut allergy. Pediatr Allergy Immunol 1995;6:95-7.

40. Werfel T, Morita A, Grewe M, et al. Allergen specificity of skin-infiltrating $\mathrm{T}$ cells is not restricted to type- 2 cytokine pattern in chronic skin lesions of atopic dermatitis. J Invest Dermatol 1996;107:871-6. 